\title{
A Longitudinal Study of Children's Theory of Mind and Drawings of Play
}

\author{
Sandra L. Bosacki ${ }^{1}$ \\ ${ }^{1}$ Faculty of Education, Brock University, 500 Glenridge Ave., St. Catharines, ON L2S 3A1, Canada \\ *Correspondence: Faculty of Education, Brock University, 500 Glenridge Ave., St. Catharines, ON L2S 3A1, \\ Canada. Tel: 1-905-688-5550 ext. 4987. E-mail: sandra.bosacki@brocku.ca
}

Received: January 15, 2013

Accepted: March 21, $2013 \quad$ Online Published: August 30, 2013

doi:10.5430/wje.v3n5p13

URL: http://dx.doi.org/10.5430/wje.v3n5p13

\begin{abstract}
This study investigated the longitudinal relations between theory of mind (ToM) understanding and children's drawings of play in 26 school-aged children, (16 females, 10 males, aged 8-12 years). Theory of mind was assessed at Time 1 (T1, $M=8 \mathrm{y} 5 \mathrm{~m}$ ) and two years later at Time $2(\mathrm{~T} 2, M=10 \mathrm{y} 4 \mathrm{~m})$, as well as children's drawings of play activities. Longitudinally, significant positive associations $(p<.05)$ were found between T1 ToM ability and the T2 verbal description of the child's drawing $(r=.38)$. A significant negative correlation was found between children's verbal descriptions of their drawings and emotional facial expressions $(r=-.44)$. The majority of the drawings reflected physical play activities, with physical, competitive activities (e.g., soccer). Implications for socioemotional and cognitive development in middle childhood are discussed.
\end{abstract}

Keywords: middle childhood; theory of mind; play; emotion; gender

Although children's Theory of Mind (ToM) development or the ability to understand thoughts and emotions in self and other is an active area of research (Dunn, 2008), the development of the ability to represent and reason from second-order beliefs (two or more mental states) has received relatively little attention in the literature particularly during the transition from middle to late childhood (e.g., 8 - 12 years) (Carpendale \& Chandler, 1996; Carpendale \& Lewis, 2004; see Miller, 2009 for a review). This is surprising, given that social communication depends mainly on what people believe about other people's beliefs (Astington, 1993). The importance of second-order or interpretive reasoning has been shown in relation to children's ability to understand speech acts such as lies, jokes, sarcasm, and irony (Filoppova \& Astington, 2008, 2010; Leekam, 1993), and in their ability to understand self-representational display rules (Banerjee \& Yuill, 1999; Banerjee \& Watling, 2007). Given that advanced or higher order social reasoning may also help adolescents understand the ambiguous nature of personal and social silences (Bosacki, 2008), some researchers suggest such advanced reasoning is also fundamental to adolescents' understanding of self-conscious or social moral emotions (e.g, embarrassed, proud, etc.), their sense of self and other persons, and social interactions (Hughes, 2011).

Regarding the further development of ToM throughout childhood, recent evidence suggests that emotion understanding also continues to develop during middle childhood to late childhood (approximately during the ages 8-12 years) (see Miller, 2009 for a review), particularly regarding the understanding of complex and ambiguous emotions (Pons, et al. 2003, 2004; Yuill \& Coutlas, 2007). In contrast to the simple or basic emotions (e.g., happy, sad), to understand complex or socio-moral emotions (e.g., pride, embarrassment), children must hold in mind two separate pieces of information: other people's and societal norms (Saarni, 1999). That is, children must imagine what others think of their behaviour and self-evaluate their behaviour against internalized behavioural standards. Although engaging in social interactions, especially during middle childhood involves complex social and emotional understanding and hinges on cognitive abilities such as second-order, to date, few studies have investigated the links between these concepts during middle to late childhood, especially within the context of play and social interactions (Hughes, 2011). Given this gap in the literature, this study will investigate individual differences in social cognition within the school context during middle childhood. 


\section{ToM and Social Experiences in School Context}

Although ToM and social interactions would seem to be foundational to a child's educational experiences (Bruner, 2006), few researchers have studied the relations between ToM understanding and school experiences beyond the age of 8 or 9 either within the family or school context (Astington \& Pelletier, 1997; Hughes, 2011). Similar to the rich family context, the school classroom provides children with a valuable opportunity to learn social and emotional messages regarding interactions and others' mental states. Regarding academic competence and school success, associations have been found between ToM and the production of stories and general language ability (Astington \& Jenkins, 1995; McKeough, 1992). Theory of mind understanding has also been claimed to facilitate children's ability to self-monitor and regulate their cognitive process and engage in reflexive thinking (Lagattuta \& Wellman, 2002).

This study focuses on children in middle to late childhood because knowledge about self and others' thoughts and emotions continues to develop during middle to late childhood which is crucial to effective social functioning within play contexts (Hughes, 2011). Between 3 and 7 years of age, children also begin to understand that the focus of a person's thoughts can change or shape emotions as well as actions, especially within a play context. For example, a person may begin to feel sad if she or he suddenly remembers an upsetting experience and they could begin to feel and act nervous or worried just by imagining a negative event that might happen in the future (Lagattuta \& Wellman, 2002). Relatedly, research on children's social and emotional coping and problem-solving strategies further suggests that, between 5 and 10 years of age, children increasingly understand that people can use their minds to control their emotions and actions-even in the absence of a change in the external situation - by using strategies such as distraction or cognitive reframing (Hughes, 2011).

Despite this strong base of research on children's understanding of how thoughts influence emotions and vice versa within social experiences, we know little about older children's ToM understanding and their perceptions and experiences of play. Research studies suggest that ToM understanding is linked to higher-order, metacognitive thought or more advanced reasoning (Miller, 2009). That is, children who possess high levels of ToM understanding or provide psychological explanations are more likely to "think about their own and others thinking" and engage in critical philosophical enquiry and shared dialogue during the school day (Haynes, 2002). Thus, given that teaching and learning is crucial to self- and ToM understanding (Bruner, 1996), this study explores how children's ToM understanding plays a role in their perceptions of play within the middle school years (Ladd, Buhs, \& Troop, 2002). Also, as Hughes (2011) states, a relatively small number of studies have examined individual differences in social understanding in relation to children's own views of themselves within the context of their middle school experiences.

\section{Gendered Children's Perceptions of Play and ToM Understanding}

Given that gender values and beliefs of adults, peers, and mass media may influence children's sense of gender-roles, and that gender-related beliefs may be reflected in children's drawings and descriptions, it seems puzzling that little research has explored the gendered nature of children's drawings of play (Anning \& Ring, 2004). The few existing studies show that children's spontaneous drawings (ages 3-10 years) reveal that boys' drawings tend to sometimes illustrate actions involving violence and destruction, machinery and sports contests. In contrast, past research shows that majority of drawings by girls may depict more tranquil scenes of family life, landscapes, and children at play (Richer, 1990). Research findings suggest that boys are more likely to depict exploits, conflict, and displays of power and motion, whereas girls are more likely to draw happy girls and small animals, with smaller, more controlled diagrams, particularly regarding emotional content (Burkitt, Barrett, \& Davis, 2003; Dyson, 1989; Thomas \& Silk, 1990).

Nevertheless, the research findings on gender-related differences in ToM remain contradictory and inclusive, as some studies show that females possess higher levels of ToM understanding (e.g., Bialecka-Pikul et al., 2010; Bosacki \& Astington, 1999; Charman et al., 2002), others that boys possess higher levels of ToM understanding than females (Russell et al., 2007), or still others no gender differences at all (Astington \& Jenkins, 1995). Recently, a few studies have found positive connections between children's ToM understanding, self-concept, and their drawings of play and also jokes or funny situations (Bosacki et al., 2008; Kielar-Turska-Bialecka-Pikul, 2010). Given the possible influence of peers and teachers on children's perceptions of self and others engaged in play activities, it is surprising that few studies investigate children's understanding of play and ToM in childhood. As Hughes (2011) suggests, the moderating role of gender in the relation between ToM and social experiences requires further investigation. 
Gardner's (1982) work with children and art activity revealed that girls are more likely than boys to excel in mixed media, symbolic play, narrations, and three-dimensional forms, whereas boys were more likely to excel with clay or single-medium tasks. Gardner also found that boys were more likely than girls to represent a certain character or superhero such as Batman, whereas girls are more likely to represent themes of fairy tales including animals such as princesses on horses (Golomb, 1990). Overall, the few studies on gender-related differences in drawings suggest that girls and boys produce different kinds of drawings, particularly with regard to the size and content of drawings (e.g., Burkitt et al., 2003; Koppitz, 1969).

Accordingly, this study investigated the individual differences in, and the relations between adolescents' ToM understanding and their perceptions of play over time. More specifically, the present study addressed the following questions: 1) Do longitudinal relations exist among children's ToM understanding at Time 1 and their perceptions of play at Time 2 (2 years later); and[:] 2) Do individual differences in children's scores and correlational patterns among variables exist at both time points (8 years and 10 years of age)?

\section{Method}

\subsection{Participants}

As part of a larger longitudinal study of children's ToM understanding of mental states and emotions in self and others), and its relation to social cognitive and emotional competencies (Bosacki, 2008), this exploratory, small-scale, longitudinal, correlational study focused on two time points (T1, 2006; $M=8 \mathrm{y} 5 \mathrm{~m}$ ), and (T2, 2008; $M=10 \mathrm{y}, 4 \mathrm{~m}$ ), and involved 26 (16 females, 10 males) mainly Euro-Canadian children from two schools within middle SES, semi-rural neighbourhoods.

\subsection{Procedure}

Upon obtaining ethical clearance from the universities, school board, principals, teachers, parents, and students, the study focused on the results each year when children completed standardized pencil and paper measures and participated in individual interviews that involved social stories to assess children's emotional and ToM understanding (e.g., how did they interpret mental states in others) and their perceptions of self and play. Only those children who received written parental permission and agreed verbally participated in the study.

Data collection each year (T1 and T2) consisted of two stages. The first stage took place during the fall term within the school and consisted of a group, in-class session where three trained female researchers group-administered a drawing task to assess children's perceptions of play (see below). To facilitate task completion, researchers provided explicit written (on the blackboard) and verbal task instructions to the children. Following this group instruction session, one researcher read aloud the questionnaire items to the participants and the children completed the task individually within the classroom. The two remaining researchers monitored the class session and addressed any questions that children had as they completed the task. This task was completed within a 30 minute class period.

The second stage occurred during the winter term and consisted of an individual session in which children were involved in interviews to explore their perceptions of the drawing they created in the fall, as well as their ToM understanding as measured by two socially ambiguous stories (see below). Interviews were conducted in a small room outside of the classroom and all interviews were audiotaped and transcribed. The interview session was approximately 20-30 minutes in length. Demographic information pertaining to family structure was obtained through a parent questionnaire. Three trained female researchers administered all tasks, and children were reminded that their responses would remain confidential, and that they had the opportunity to ask questions or stop at any time during the research.

This study focused on tasks conducted during two time points, the ToM story interviews (T1, February-April 2006) and T2 measures (November-February, 2008/9) including the play drawings. As noted above, the play drawing task was group-administered within class, whereas the ToM story-interview tasks were conducted within a quiet room outside of the classroom during school time. Interviews were audiotaped for subsequent transcription and analysis.

\subsection{Data Sources}

Theory of Mind Understanding (Social Ambiguous Stories) (Bosacki, 2000; Bosacki \& Astington, 1999). Gleaned from past research, to assess ToM understanding or understanding other's mental states and emotions), adapted versions of two brief vignettes (consisting of an ambiguous social situation) that describe an ambiguous social event with three children (one for girls, one for boys) were read to the child (Bosacki, 2008). Borrowing from theoretical work that views ToM as a vehicle or instrument used to co-construct or narrate ones' social reality (Astington, 1993; 
Bruner, 2006), and studies that investigate an advanced ToM through narratives (Charman \& Shumeli-Goetx, 2008; Happe, 1994), this task aimed to asses the ToM involved in interpreting social meaning from ambiguous stories.

The stories were socially ambiguous because past research has found children's interpretations of ambiguous social situations to be an effective method of eliciting children's representational understanding of mind and emotion (Dodge \& Frame, 1982; Levinson, 1995). Thus, this task was developed to strike a balance between projective, open-ended narrative tasks (e.g., Fox, 1991; Selman, 1980), and forced-choice, experimental tasks (e.g., see Baron-Cohen, 2011). The two stories involved one scenario for girls and another for boys (an unfamiliar girl approaches two friends already engaged; two boys on a sports team need to choose another boy for their team). However, no reason was given in this story to explain why the actors did not speak to the recipient. Thus, participants had to infer the reason that the actors disregarded the recipient. The following stories are excerpts from the Nancy/Margie and Kenny/Mark Social Ambiguous Story Interviews used to assess participants' understanding of emotions and mental states (Bosacki, 2000).

Nancy/Margie

Nancy and Margie are watching the children in the playground. Without saying a word, Nancy nudges Margie and looks across the playground at the new girl swinging on the swing set. Then Nancy looks back at Margie and smiles. Margie nods, and the two of them start off toward the girl at the swingset. The new girl sees the strange girls walk towards her. She'd seen them nudging and smiling at each other. Although they are in her class, she has never spoken to them before. The new girl wonders what they could want.

\section{Kenny/Mark}

Kenny and Mark are co-captains of the soccer team. They have one person left to choose for the team. Without saying a word, Mark winks at Kenny and looks at Tom who is one of the last children left to be chosen. Mark looks back at Kenny and smiles. Kenny nods and chooses Tom to be on their team. Tom sees Mark and Kenny winking and smiling at each other. Tom, who is usually one of the last to be picked for team sports, wonders why Kenny wants him to be on his team.

The stories were followed by questions that assessed emotion understanding, including emotion word labelling and understanding of situational causes of emotions. In addition, following each narrative, the children were asked to imagine and predict what the characters would do next, what they might or could be thinking and feeling, and whether or not the actions would be considered the 'right' or 'wrong' thing or moral judgements. They were also asked to imagine what would happen next in the story. Based on past research (see Bosacki, 2000), responses to each emotion were coded according to their accurateness (mental state and emotional labelling), and their level of conceptual sophistication (understanding of the socially ambiguous situation, or what causes emotions for both self and peer). For example, a code of 0 was provided for intangential or "I don't know responses."; $1=$ behavioral/physical responses such as "Tom would walk away and play elsewhere."; 2 = Psychological that would include references to at least 1-2 psychological or emotional state such as "Tom thought that Kenny and Mark were unfair.”; and 3 = Integrated psychological response which would be a sophisticated response involving a complex (3 or more), and/or contradictory combination of psychological emotional terms (e.g., "Tom felt that Kenny and Mark were angry with him and wanted to trick him into thinking they were his friends.”).

Cronbach's alpha for the 21-item aggregate score for the Nancy/Margie/new girl and Kenny/Mark/Tom story was .67 and .69 respectively. To obtain as sensitive a ToM measure as possible, children's scores on the Nancy/Margie/new girl and Kenny/Mark/Tom (0-21) were summed into a reliable composite (0-42). For the present sample, Cronbach's alpha for the sum of these two scores was $\alpha=.69$. Consistent with past research (Bosacki), this was deemed to indicate modest, but adequate, internal consistency to use the combined total score as our main index of Time 1 ToM understanding $(M=23.34 ; S D=4.56$, range $0-42)$. Randomly selected $25 \%$ of the transcripts were coded by a second independent coder, resulting in an average kappa of (.92) across the two stories.

Play Illustrations. Once children completed the self-report questionnaires, each child was asked to draw a picture of themselves playing on a "8-X 11" blank piece of paper, with a box of 8 crayons. They were also asked to circle themselves in the picture and, depending upon their ability to write a story and/or a few words, to describe their drawings on the back of the papers.

Coding of Play Illustrations and Descriptions. To explore individual differences, building on previous research (e.g., Richer, 1990), the content of the drawings and stories were analyzed qualitatively for themes such as type of play (physical $=1 /$ non-physical activities $=2$, competitive $=1$, autotelic or solitary $=2$ - -cooperative $=3$ ), setting $(1=$ classroom, $2=$ home, 3 =playground/outdoors), number of characters, verbal content $(1=$ no verbal content, $2=$ speech 
balloons), emotional facial expressions of characters in the drawings (1=sad, $2=$ neutral or no expression, $3=$ happy), and external objects (1=natural (sun/grass) $2=$ (cats/dogs) $3=$ =play materials (e.g, ball/skipping rope) 4=building/house/school/pool $5=$ no external objects). In addition to the macrolevel codes of physical/non-physical, specific activities depicted in the drawings, other activities were also noted, including swimming, playing ball, and playing with animal companions. The number of characters portrayed in the drawings were also recorded. All drawings $(N=26)$ were coded by an independent second rater. Kappas for the various categories of codes ranged from .80-1.00 suggesting relatively high inter-rater reliability.

\section{Results}

\subsection{Descriptive Statistics and Preliminary Analysis}

Data analysis based on a coding scheme developed from previous research was derived from the ToM interview questions to create a composite ToM understanding score (Bosacki, 2000). Thus, higher ToM scores represented a more sophisticated understanding of emotion and mental state concepts.

\subsection{Task Performances and Individual Differences}

\subsubsection{Frequencies}

First, the numbers of children producing each of the different types of cognitive and emotion words during the drawing task were calculated. Table 1 shows the distribution of females' and males' scores on the ToM tasks as well as the drawing tasks. Table 1 shows that the T-test analysis revealed one marginally significant gender-related difference for the number of characters drawn in the play pictures with females drawing a greater number of human characters than males.

Table 1: Means and Standard Deviations of Main Variables for Time 1 and Time 2

\begin{tabular}{|c|c|c|c|c|c|c|}
\hline \multirow[t]{2}{*}{ Variable } & \multicolumn{3}{|c|}{ Time $1(n=26)^{1}$} & \multicolumn{3}{|c|}{ Time $2(n=26)^{3}$} \\
\hline & $\begin{array}{l}\text { Total } \\
M(S D) \\
\mathrm{n}=26\end{array}$ & $\begin{array}{l}\text { Females } \\
M(S D) \\
\mathrm{n}=16\end{array}$ & $\begin{array}{l}\text { Males } \\
M(S D) \\
\mathrm{n}=10\end{array}$ & $\begin{array}{l}\text { Total } \\
M(S D) \\
\mathrm{n}=26\end{array}$ & $\begin{array}{l}\text { Female } \\
M(S D) \\
\mathrm{n}=16\end{array}$ & $\begin{array}{l}\text { Males } \\
M(S D) \\
\mathrm{n}=10\end{array}$ \\
\hline \multicolumn{7}{|l|}{ Theory of Mind Total $(n=26)^{1}$} \\
\hline ToM Total $^{2}$ & $\begin{array}{l}27.29 \\
(19.17)\end{array}$ & $\begin{array}{l}30.06 \\
(18.32)\end{array}$ & $\begin{array}{l}20.30 \\
(20.97)\end{array}$ & $\begin{array}{l}39.00 \\
(3.42)\end{array}$ & $\begin{array}{l}39.934 \\
(3.80)\end{array}$ & $\begin{array}{l}37.8 \\
(2.7)\end{array}$ \\
\hline \multicolumn{7}{|l|}{ Drawing Variables $(n=26) 3$} \\
\hline Number of Characters4 & & $2.29(2.11)$ & & $3.0(2.39)$ & & $1.6(1.08)^{\mathrm{M}}$ \\
\hline Emotional Facial Expressions5 & & $2.67(.83)$ & & $2.88(.34)$ & & $2.6(.97)$ \\
\hline \multicolumn{7}{|c|}{ Drawing Text and Drawing Description Word Counts6 } \\
\hline Total Word in Drawing Text & & $04(13.77)$ & & $13.06(13.37)$ & & $12.80(15.36)$ \\
\hline Number of Emotion Terms in Drawing $\mathrm{T}$ & & $.57(.39)$ & & $.69(1.19)$ & & $.50(.53)$ \\
\hline Number of Cognitive Terms in Drawing & Text & $.18(.96)$ & & $.19(.40)$ & & $.20(.42)$ \\
\hline Total Number of Words in Drawing Desc & rription & $18.42(17.59)$ & & $23.44(19.06)$ & & $14.10(13.52)$ \\
\hline Number of Emotion Terms in Drawing D & escription & $1.00(1.68)$ & & $1.19(1.87)$ & & $.90(1.52)$ \\
\hline Number of Cognitive Terms in Drawing & Description & $.54(.99)$ & & $.69(1.25)$ & & $.40(.52)$ \\
\hline
\end{tabular}

Note. 1. Mean Age $=8$ y; 5 mos., Females $\mathrm{n}=16$, Males $\mathrm{n}=10$. 2. Total Theory of Mind Score (Bosacki, 2000); range 0 - 42; higher scores reflect higher ToM understanding, $T(1,27)=3$. 35, $p<$. 01, Mean Age: $10 \mathrm{y}$; 4 mos., Females $=\mathrm{n}=16$, Males, $\mathrm{n}=10$. 4. Number of Characters drawn, range 0-9. 5. Emotional Facial Expressions $=0=$ uncodable, 1 = negative emotion, 2 = neutral, 3 = positive. 6 . $T$-Test analysis found no significant gender-related differences.

M. $T=-1.733(2,24), p<.10)$.

The majority of the drawings reflected physical play activities (21/26 or 81\%), with physical, competitive activities such as soccer or baseball occurring most frequently (9/26, 35\%), followed by autotelic or solitary activities such as swimming, dancing, or reading $(7 / 26,27 \%)$, followed by physical, cooperative activities such as soccer and basketball as well as talking with friends (5/26, 19\%). 


\subsubsection{Frequency of Drawing Variables (Pictorial Content)}

Extending the research of Richer (1990), the drawings were analyzed according to whether the activities were physical or non-physical, and if they were cooperative, competitive, or autotelic/solitary. Table 2 shows that overall, the majority of activities were physical activities - both autotelic/solitary such as swimming or playing basketball by oneself, or competitive physical games such as soccer, basketball with others. The least common was non-physical competitive which was not drawn (e.g., competitive board games such as chess or checkers).

Table 2: Frequencies and Percentage of Depicted Play Activity in Females and Males

\begin{tabular}{lllllll}
\hline & & $\begin{array}{l}\text { Total } \\
(N=26)\end{array}$ & \multicolumn{2}{c}{$\frac{\text { Females }}{(n=16)}$} & & $\frac{\text { Males }}{(n=10)}$ \\
\hline Activity Level & Physical & Non-Physical & Physical & Non-Physical & Physical & Non-Physical \\
\hline Play Activity & & & & & & \\
1. Cooperative & $5(19 \%)$ & $1(4 \%)$ & $5(31 \%)$ & $1(6 \%)$ & $0(0 \%)$ & $0(0 \%)$ \\
2. Competitive & $8(31 \%)$ & $0(0 \%)$ & $4(25 \%)$ & $0(0 \%)$ & $4(40 \%)$ & $0(\%)$ \\
3. Autotelic & $8(31 \%)$ & $4(15 \%)$ & $4(25 \%)$ & $2(13 \%)$ & $4(40 \%)$ & $2(20 \%)$ \\
Total & $21(81 \%)$ & $5(19 \%)$ & $13(81 \%)$ & $3(19 \%)$ & $8(80 \%)$ & $2(20 \%)$ \\
\hline
\end{tabular}

Note. Frequencies did not differ at the $p<.05$ level.

Regarding gender differences, consistent with past research (Richer, 1990), females were marginally more likely than males to draw themselves playing cooperatively or engaging in social activities (Chi-Square analysis, $X^{2}$ (2, 26, 5.088, $p=.079$ ). Furthermore, the most common activity among females was physical cooperative activities such as group dancing, slumber parties, etc., whereas no males drew this kind of play activity. Among males, the most common were competitive and autotelic/solitary physical activities such swimming or playing basketball, hockey either alone or with friends. Chi-square analyses were conducted on these activity categories but frequencies did not differ at the $p<.05$ level.

\subsection{Content Analysis of Play Illustrations and Narrative Text}

In general, findings from the content analysis of both the drawings and narratives revealed gendered themes of play experiences (see Tables 1 and 2). In both modes of representation, females referred to more social and psychological aspects of play whereas males focused mainly on physical activities. Although nonsignificant, Table 3 illustrates that an analysis of the means showed that compared to males, there was a trend for females to include more text in their drawings, as well as in their narrative descriptions during the interviews. In addition, compared to males, females were more likely to include emotional and cognitive terms in both their drawing text, as well as in their drawing descriptions.

Table 3: Titles of Play Drawings in Females and Males

\begin{tabular}{lll}
\hline \multicolumn{1}{c}{$\begin{array}{c}\text { Females } \\
(n=16) \\
\text { Physical }\end{array}$} & Non-Physical & \multicolumn{1}{c}{$\begin{array}{c}\text { Males } \\
(n=10)\end{array}$} \\
& Physical & Non-Physical \\
\hline Me and my Friends at a Dance & Thinking about Books & Playing with Dog \\
What I like to Do & Me and all my Friends & \multicolumn{2}{l}{ Paintballing with my Friends } \\
Soccer Year & Slumber Party & Hockey \\
My Time Outside & & The Butterfly \\
The Summer with my best Friend N and L & & Soccer Story \\
& & Playing Baseball \\
& & Dodge Ball \\
\hline
\end{tabular}

According to Willat (2005), given that characters depicted in a child's drawing may represent social relationships, we examined the number of characters drawn by the children. Regarding the additional characters within the drawings such as friends and/or family members, the majority of children 10/26 (38\%) drew themselves only (self-portraits), with 7/26 (27\%) drawing at least 2 people, and 7/26 (27\%) 3 or more characters, with one girl drawing herself with 8 other friends. Interestingly, only one child (male) did not include himself in the drawing as the drawing illustrated an empty basketball courtyard with the story text "I like to play basketball everyday. It is very fun. I am very good at basketball." Further to this story text, when asked during the interview to describe his drawing, he stated to the researcher, "I like to play basketball mostly everyday but I can’t now cause there's snow but its fun 
because it's a competitive thing and I am competitive so its fun to complete against other people. I guess I'm good at basketball” (11 year old male, January, 2009). Regarding the inclusion of animals as play companions, two children drew themselves playing with an animal companion (one male petting a cat, one male playing with three dogs).

Regarding the emotional display on the characters drawn by the participant, the majority of drawings depicted positive facial expressions 22/26 (85\%), and 3/26 (12\%) (2 F, $1 \mathrm{M}$ ), whereas 1/26 (4\%) (1 M) depicted negative facial expressions (sad/angry), and 1/26 (4\%) (1M) did not include any human figure in the drawing.

Regarding the inclusion of external objects in the drawings, the majority of children 19/26 (74\%) included at least 1 external object, whereas only 5/26 (19\%) preferred to draw a self-portrait with no background/setting or any external features to the drawing. The most common objects drawn by the children included 9/26 (35\%) included both buildings and play materials such as a house or school with play equipment (e.g., balls, hockey sticks, etc.). The second most common $(8 / 26,31 \%)$ drawing included reference to nature (such as sun, grass) as well as play objects or equipment (e.g., ball or trampoline) ( $3 \mathrm{Hi}$ ToM, 5 Low ToM). The majority of drawings were set in the outdoors or natural setting such as a school yard, outside of the home 23/26 (88\%), whereas 3/26 (12\%) of the drawings represented activities inside the participant's (all females) home. Interestingly, two of the drawings showed solitary activities such as reading a book, whereas the other drawing illustrated the participant watching television in her home. The third indoor drawing referred to a social activity that involved a slumber party or the sleeping over at another one's house.

Overall, the majority of children' perceptions of play reflected physical, mainly social activities such as organized sports or talking, socializing with friends (e.g., slumber party). Interestingly, only one drawing reflected a reference to the role technology plays in play activities as there were no children who drew pictures of computers, smart phones, video games, etc. Results showed that only one drawing included a television as one female drew a picture of herself watching her favourite television show in her home. Given the vague research instructions to "Draw a picture of yourself playing," this is surprising given that the interviews took place in the fall term of 2008 when many children in later childhood (10-12 years) may have already engaged been engaged in the digital era of play (Turkle, 2011).

Regarding the inclusion of voice bubbles or text in the drawing, 21/26 (81\%) of children included either voice bubbles or text in drawing with 2 drawings illustrated voice bubbles. For example, one 11 year old male drew a voice bubble stating, "Kitty a cute Kitty" on the drawing of the male petting the cat. The second drawing to include a voice bubble illustrated a male playing hockey and stated "Goal."

\subsection{Longitudinal and Cross-Sectional Correlational Analysis}

Significant positive associations $(p<.05)$ were found between ToM ability at T1 and the verbal description of the child's drawing in T2 $(r=.378)$. Marginally significant correlation was found between T1 and T2 ToM ability $(r$ $=.324, p=.092)$. And paired T-test analysis showed a significant age difference $(T(1,25)=3.35, p<.01)$ in ToM $\mathrm{T} 1$ and $\mathrm{T} 2$ scores as reflected in the increase of ToM scores from T1 (age 8) to T2 (age 10): T1 $(M=27.2857, S D=$ 19.17) and T2 $(M=39, S D=3.42)$. In contrast, independent T-test analyses for T1 and T2 showed no significant gender differences between the scores for males and females.

An examination of the ToM means showed that children who depicted drawings of cooperative. non-physical activities (e.g., talking and visiting with friends, etc.) received the highest T1 ToM scores $(M=47.00, S D=20.308)$, whereas children who completed drawings of competitive, physical games (e.g., soccer, basketball, etc.) received lowest T1 ToM scores $(M=21.25, S D=1.42)$.

\subsection{Longitudinal Individual Differences}

Examination of the means of the main variables (Gender, T1 ToM, and T2 drawing variables) showed no significant main variable effect for ToM at T1 and a marginally significant difference for gender with females drawing a higher number of characters in their play drawings $(M=3, S D=2.39)$ compared to males $(M=1.6, S D=1.6, T=-1.733, p$ $=.096$ ) (see Table 2). To examine for further individual differences among the means of the main variables, further exploratory analysis was conducted by creating groups based on median splits between high and low groups of scores (High /Low ToM, High/Low Global Self-Worth, High/Low Physical self-worth, and High/Low behavioural conduct) revealing no significant differences among the scores of the main variables.

\subsection{Cross-sectional and Longitudinal Correlational Analysis}

Correlational analysis was conducted cross-sectionally between aggregate ToM scores at $\mathrm{T} 1$ and $\mathrm{T} 2$, as well as between children's perceptions of play and text at T2. Longitudinally, correlations were conducted between T1 ToM 
and T2 perceptions of play in drawings and text.

Regarding cross-sectional correlations, at Time 2, correlations between children's perceptions of play as revealed through both drawing and text revealed a significant negative correlation $(r(24)=-.44, p=.03)$ between children's cognitive description of their drawing and their drawing of negative emotional expressions, that is, the more likely children used cognitive terms in their description of their drawings (e.g., think, believe, etc.) the more likely they were to draw themselves with sad facial expressions during their play activities. Alternatively, the less likely children were to include cognitive terms in their verbal description of their play drawings, the more likely they were to depict themselves with positive or happy emotions. This association suggests a connection between children's use of cognitive terms to describe play activities and their visual depiction of their emotional experiences during play.

Verbal content (i.e. total word count) of drawing descriptions or the number of characters drawn were not correlated with story text found within the drawings, although significant $(p<.01)$ positive correlations were found between the number of characters drawn in child's play pictures and their total word count of verbal description of their drawings $(r(24)=.61, p<.001)$ as well as the number of emotion words $(\mathrm{r}(24)=.52)$ and number of cognitive words $(r(24)$ $=.49)$

Regarding longitudinal relations, children's ToM understanding at T1 and their perceptions of play at T2 showed significant positive correlations between T1 Total ToM scores and the mental state language used within children's verbal descriptions of play at T2: $r(24)=.38, p<.05$, especially their use of emotion terms when describing their play drawings $(r=.323, p=.09)$. A marginally significant correlation was found between T1 and T2 ToM scores $(r$ $=.35, p=.06$ ), although interestingly, $\mathrm{T} 2 \mathrm{ToM}$ scores were not related to any of the $\mathrm{T} 2$ drawing variables. These results support previous research that found complex connections between ToM and dramatic art activities (Goldstein \& Winner, 2012; Kielar-Turska \& Bialecka-Pikul, 2010).

Separate correlational analyses for each gender revealed a positive significant correlation between T1 ToM scores and emotional description of play for males only $(n=10, r=.643, p=.045)$, whereas for females, there was no significant correlation ( $n=16, r=.152, n s)$. For females only, a significant negative correlation was found between $\mathrm{T} 1 \mathrm{ToM}$ scores and emotional facial description of participants' self-portrait $(r=-.674, p<.01)$. That is, the higher the ToM scores, the more negative the facial emotion (sad), or vice versa - the lower the ToM score, the drawings showed more positive facial expressions (happy). In contrast, for males there was no relation $(r=-.247, n s)$. Finally, a significant positive correlation for females was found between T1 ToM scores and their verbal description of their drawings at T2 $(r=.513, p=.042)$, whereas no relation was found for males $(r=.244, n s)$.

In sum, associations between children's ToM understanding and their perception of play across time holds many educational and clinical implications that will be discussed in the next section.

\subsection{Content Analysis of Drawing Titles}

Participants were also asked to provide a title for her/his drawings once finished and 15/26 (58\%) of total drawings included titles ( $8 / 16$ or $50 \%$ females, $7 / 10$ or $70 \%$ males). Table 3 shows the distribution of the titles across both genders. Although all children's drawing titles reflect the focus of their drawings on physical play activities such as organized sports or dance $(12 / 15,67 \%)$, the participants' language choice for their titles suggests a focus on the key personal meanings of their drawings. For example, compared to males, females' titles reflected a greater diversity across both physical (5/8,63\% of drawings)-and non-physical (3/8, 38\%) titles, with more references to identity, friends, and social activities. In contrast, $100 \%$ of males' titles represented physical activities with only one references to friends. All children focused mainly on social activities whereas only two titles referred to solitary activity (one non-physical - "thinking about reading," another drawing entitled "Butterfly" referred to solitary swimming), with one reference to an animal companion.

\subsection{Silences and Contradictions in the Data}

In addition to describing what children drew and reported in the present study, we were also interested in describing what topics the children chose not to draw - that is, what were the silences in the children's drawings of play? Overall, the drawings showed a lack of electronic toys/computer, given that only 1/26 (female) (4\%) drew herself watching television with her friends, and no children drew pictures of themselves playing electronic and or video games, on a computer or the Internet, or using a personal communication device such as a smart phone. Regarding gender differences, in contrast to past research which suggests that females are more likely than males to draw animals (Dyson, 1989), the present study showed that males were more likely than females to include animals in their drawings $(2 / 10 ; 20 \%$ of males, $0 \%$ of females); both drawings depicted males playing with their animal companions - one cat and one dog respectively. Also, given the limited amount of text and numeric representation in 
the drawings, only one participant (female) depicted both numeric and textual content in her drawing ("I read for 3 hours everyday. Reading is sweet.”) (10 year old female, November, 2008).

\section{Discussion}

This study examined the longitudinal links between children's ToM understanding and their perceptions of play at approximately 8 years of age and then 2 years later at approximately 10 years of age. This study offers a unique contribution to the existing literature regarding ToM in later childhood because by focusing on a relatively smaller number of participants (as compared to larger-scale quantitative survey studies), we provided an in-depth exploration of children's perspectives. Accordingly, the main findings are discussed in terms of the following research questions: 1) Do longitudinal relations exist among children's ToM understanding and their perceptions of play at 8 years of age and then 2 years later, at 10 years of age, and : 2) Do individual differences in children's scores and correlational patterns among variables exist?

Regarding the first research question, examination of the means showed significant age effects for ToM understanding scores; the older the children, the higher the ToM understanding scores. An examination of the ToM means showed that children who depicted drawings of cooperative. non-physical activities (e.g., talking and visiting with friends, etc.) received the highest T1 ToM scores, whereas children who completed drawings of competitive, physical games (e.g., soccer, basketball, etc.) received lowest T1 ToM scores.

Regarding the second research question, correlational analysis revealed that significant positive relations existed between ToM scores at T1 (approximately 8 years old), and children's psychological descriptions, particularly their emotional descriptions of play two years later when children were approximately 10 years old. The separate correlations for gender revealed a positive significant correlation between T1 ToM scores and T2 emotional description of play for males only. In contrast, for females, there was no significant correlation. For females only, a significant negative correlation was found between $\mathrm{T} 1 \mathrm{ToM}$ scores and $\mathrm{T} 2$ emotional facial description of participants' self-portrait (i.e., higher ToM scores were associated with a larger number of drawings that reflected negative or sad facial expression or vice versa, a higher number of drawings that showed positive or happy facial expressions were associated with lower ToM scores). In contrast, there was no relation for males. Finally, a significant positive correlation for females was found between T1 ToM scores and their verbal description of their drawings at $\mathrm{T} 2$, whereas no relation was found for males.

How do we explain these findings? From a psychocultural and social cognitive perspective, (e.g., Bussey \& Bandura, 2004; Maccoby, 1998) the present findings can be explained in terms of the interplay between psychological and emotional understanding and children's perceptions of play during middle childhood. The relations reflect the psychological complexity of children's perceptions of play, specifically the importance of understanding thoughts and emotions in others. Although the findings suggest that ToM's role in children's emotional experiences perceived during play may be influenced by the gender of the child, our findings also showed a more sophisticated ToM related to negative play perceptions among females, and positive play perceptions among males.

Regarding the relation between higher ToM understanding and females' drawings of negative emotions on their facial expressions depicted within the play pictures, our findings suggest that females with a more sophisticated sense of ToM understanding are more likely to understand the emotional complexity and sometimes ambiguous and negative emotions involved in play experiences as expressed in their drawings. Given that this finding was for females only, perhaps the finding reflects stereotypic societal gender-role expectations which may place a greater value on emotional competence among women as compared to men (Fine, 2010). Perhaps the females in the present study learned that understanding emotional worlds is an expectation of their gender, and, thus, competence in this "emotion reading skill” would be more likely to influence their perceptions of play.

The present findings suggest that complex gendered connections (similarities and differences) exist among longitudinal relations between ToM and play perceptions. Such findings support previous research (e.g, Cutting \& Dunn, 1999; de Villiers, 1999; Jenkins \& Astington, 1996) and theorists' claims that self-perceptions and social interaction may play significant roles in children' ToM understanding and play experiences (e.g., Bruner, 1996; Cutting \& Dunn, 1999; Hughes, 2011). However, gender analyses revealed that for females only, a positive relation was found between ToM understanding and total word count in descriptions of drawing. Thus, compared to males, our findings suggest that ToM may share a stronger role in females' language development.

Although ToM played a role in children's emotional play experiences for both genders, for males only, ToM understanding was positively related to their emotional description of their play drawing[,] suggesting that for males 
only, a more sophisticated ToM was related to their reporting of positive emotional experiences during play. Perhaps this positive relation supports the claim that the play context during middle childhood is a multidimensional and dynamic process that contains various dimensions that may or may not be related to each other (e.g., Bruner, 1996; Gergen, 2001). As many social cognitive researchers claim (e.g, Bussey \& Bandura, 2004; Harter 1999; Harre, 1986), we need to know which and how self-mechanisms such as self-regulatory functions play important roles in ToM understanding and how do these mechanisms differ according to gender, ethnicity, socioeconomic status? Thus, the present findings add to the growing body of empirical evidence regarding individual differences and longitudinal relations in ToM and play experiences in middle childhood.

The titles of the children's drawings also reflected this gender-related theme, with females' titles reflecting a greater emphasis on social and cooperative activities as compared to males. The children's drawings thus reflect past research that suggests by the age of approximately 8 (i.e., the age of the youngest participants in the current study), most children have around five years of experience of largely gender-segregated peer play, where emotional closeness and conversation could be considered being much more typical of girls' play than of boys' play (Pasterki, Golombok \& Hines, 2011). As outlined in the next section, these findings support past research that suggests that children's higher ToM abilities may lead them to imagine what their friends think about them either in a positive or negative way (Hughes, 2011).

\section{Educational Significance}

Given our emphasis on the critical role ToM plays in children' play experiences, the results of this study may help to remind educators and researchers that children' mentalizing abilities and emotional experiences should not be underestimated. Educators need to be cognizant that middle to late-childhood is a time when females and males develop awareness of increased social consciousness and social pressures to conform to gender-stereotypic norms (Maccoby, 1998). This study may help to increase educators' understanding of how ToM understanding and children's play experiences may be influenced by gender within the classroom as well as other social-cultural variables not explored in this study, such as the cultural background of their families (Richer, 1990). Accordingly, the current findings may encourage educators and teachers to minimize the extent to which they use gender and cultural-stereotypic language and behaviour around grade school-aged children. Moreover, adults should be encouraged to emphasize emotional and psychological vocabulary and to articulate often how they are feeling and thinking. As noted by Kitayama et al. (1995), to provide a "thicker" description of children's ToM understanding, researchers need to examine the "emotional culture" of the middle school classroom by focusing on the influences of teachers; and peers, and others who work with children in the classroom, such as educational assistants, parent volunteers, youth workers, etc.

\section{Caveats and Conclusions}

Given the limitations of the present study (e.g., small-scale, longitudinal correlational study, lack of general intelligence measure, ethnically homogeneous sample, etc.), we offer the following interpretations of the present findings with caution. As mentioned in the introduction, given the complex process of children's co-construction of emotions, theory of mind understanding, and play experiences, semi-structured interviews with story narratives and children's drawings may not be able to capture a complete reflection of such a dynamic process.

With research on children's and early adolescents' ToM understanding and play and artistic experiences still in its infancy (Goldstein \& Winner, 2012; Hughes, 2011), this study provides a starting point for future research on ToM understanding. We recommend that such studies include observational measures in naturalistic settings such as discourse analysis of peer conversations while engaged in play activities during recess; and other social times such as snack and lunch time, as well as experiences during arts-based activities such as drawing, drama, etc. Moreover, given the complex process of emotion socialization, other factors not assessed in the present study may have influenced children's ToM understanding and perceptions of self and conversations (e.g., SES, gender of siblings, exposure to literature that focuses on mental states, etc.

Future research needs to investigate additional socialization agents who may influence the development of ToM understanding and gendered play experiences, including children's peers, teachers, siblings, and other family members, as well as the influence of media experiences with text (paper, electronic), websites, television, film, etc. (Bosacki, 2008). In sum, findings from this study suggest that longitudinal associations exist between children's ToM understanding and their perceptions of play in the middle school grades. The current findings may further the 
discourse on theory of mind development by highlighting the complexity of children' socioemotional experiences during the transition from middle to late childhood, particularly the school and play context.

\section{References}

Astington, J., \& Jenkins, J. (1995). Theory of mind development and social understanding. Cognition and Emotion, 9 , 151-165.

Astington, J., \& Pelletier, J. (1997, April). Young children's theory of mind and its relation to their success in school. Paper presented at the Biennial Meeting of the Society for Research in Child Development, Washington, DC.

Banerjee, M., \& Yuill, N. (1999). Children's understanding of self-presentational display rules: Associations with mental-state understanding. British Journal of Developmental Psychology, 17, 111-124.

Banerjee, R., \& Watling, D. (2007, June). Children's understanding of faux pas: Longitudinal associations between socio-emotional understanding and peer relations. Paper presented at the annual meeting of the Jean Piaget Society, Amsterdam, ND.

Baron-Cohen, S. (2011). The science of evil: On empathy and the origins of cruelty. New York: Basic Books.

Bialecka-Pikul, M. Rynda, M., \& Syrecka, D. (2010). Constructing a narrative in the standard unexpected transfer test in adolescence and adulthood. Psychology of Language and Communication, 14, 29-43. http://dx.doi.org/10.2478/v10057-010-0002-9

Bosacki, S. (2000). Theory of mind and self-concept in preadolescents: Links with gender and language. Journal of Educational Psychology, 92, 709-717.

Bosacki, S. (2008). Children's emotional lives: Sensitive shadows in the classroom. New York: Peter Lang.

Bosacki, S., \& Astington, J. (1999). Theory of mind in preadolescence: Relations between social understanding and social competence. Social Development, 8, 237-255.

Bosacki, S., Varnish, A., \& Akseer, S. (2008). Children's gendered sense of self and play as represented through drawings and written descriptions. Canadian Journal of School Psychology, 23(2), 190-205.

Bruner, J. (1996). The culture of education. Cambridge, MA: Harvard University Press.

Bussey, K., \& Bandura, A. (1999). Social cognitive theory of gender development and differentiation. Psychological Review, 106, 676-713.

Caravita, S., Di Biasio, P., \& Salmivalli, C. (2010). Early adolescents’ participation in bullying: Is ToM involved? The Journal of Early Adolescence, 30, 138-170.

Carpendale, J., \& Chandler, M. J. (1996). On the distinction between false belief understanding and subscribing to an interpretive theory of mind. Child Development, 67, 1686-1706.

Carpendale, J., \& Lewis, C. (2004). Constructing an understanding of mind: The development of children's social interaction within social interaction. Behavioral and Brain Sciences, 27, 79-151.

Cassidy, J., Ross, D., Butkovsky, L., \& Braungart, J. (1992). Family-peer connections: The roles of emotional expressiveness within the family and children's understanding of emotions. Child Development, 63, 603-618.

Charman, T., Ruffman, T., \& Clements, W. (2002). Is there a gender difference in false belief development? Social Development, 11, 1-10.

Creswell, J. W. (2011). Educational research: Planning, conducting, and evaluating quantitative and qualitative research. (4th Ed.). Upper Saddle River, NJ: Merrill Prentice Hall.

Cutting, A., \& Dunn, J. (2002). The costs of understanding other people: social cognition predicts young children's sensitivity to criticism. Journal of Child Psychology and Psychiatry, 43, 849-860.

Damon, W., \& Hart, D. (1988). Self-understanding in childhood and adolescence. New York: Cambridge University Press.

Dunn, J. (1995). Children as psychologists: The later correlates of individual differences in understanding of emotions and other minds. Emotion and Cognition, 9, 187-201.

Dunn, J. (2008). Relationships and children's discovery of the mind. In U. Muller, N. Budwig, \& B. Sokol., (Eds.), Social life and social knowledge: Toward a process account of development (pp. 171-182). New York: 
Lawrence Erlbaum Associates.

Dunn, L., \& Dunn, L. (1997). Peabody Picture Vocabulary Test (Third Edition). Circle Pines, MN: American Guidance Service.

Filoppova, E., \& Astington, J. (2008). Further developments in social reasoning revealed in discourse irony understanding. Child Development, 79, 126-138.

Filoppova, E., \& Astington, J. (2010). Children's understanding of social-cognitive and social-communicative aspects of discourse irony. Child Development, 81, 913-928.

Fine, C. (2010). Delusions of gender: How our minds, society, and neurosexism create difference. New York: W.W. Norton \& Company.

Gergen, M. (2001).Feminist reconstructions in psychology. Sage, Thousand Oaks, CA.

Goldstein, T., \& Winner, E. (2012). Enhancing empathy and theory of mind. Journal of Cognition and Development, $13,19-27$.

Hughes, C. (2011). Social understanding and social lives: From toddlerhood through to the transition to school. New York: Psychology Press.

Hughes, C., \& Dunn, J. (1998). Understanding mind and emotion: Longitudinal associations with mental-state talk between young friends. Developmental Psychology, $1026-1037$. http://dx.doi.org/10.1037/0012-1649.34.5.1026

Keltner, D. (2009). Born to be good: A science of a meaningful life. New York: Norton.

Kielar-Turska, M., \& Bialecka-Pikul, M. (2010). Generating and understanding jokes by five and nine-year-olds as an expression of theory of mind. Polish Psychological Bulletin, 40, 163-169.

Lagatutta, K., \& Wellman, H. M. (2002). Differences in early parent-child conversations about negative versus positive emotions. Developmental Psychology, 38, 564-580.

Layard, R., \& Dunn, J. (2009). A good childhood: Searching for values in a competitive age. London, UK: Penguin.

Lecce, S., \& Hughes, C. (2010). “The Italian job?” Comparing theory of mind performance in British and Italian children. British Journal of Developmental Psychology, 28, 747-766.

Lecce, S., Caputi, M., \& Hughes, C. (2011). Does sensitivity to criticism mediate the relationship between theory of mind and academic competence? Journal of Experimental Child Psychology, 110, 313-331.

Leekam, S. (1993). Children's understanding of mind. In M. Bennett (Ed.), The child as psychologist: An introduction to the development of social cognition (pp. 191-198). New York: Harvester Wheatsheaf.

Lewis, C., Freeman, N. H., Kyriakidou, C., Maridaki-Kassotaki, K., \& Berridge, D. M. (1996). Social influences on false belief access: Specific sibling influences or general apprenticeship? Child Development, 67, 2930 -2947. http://dx.doi.org/10.2307/1131760

Maccoby, E. (1998). The two sexes: Growing up apart, coming together. Cambridge, MA: Harvard University Press.

McAlister, A., \& Peterson, C. (2007). A longitudinal study of child siblings and theory of mind development. Cognitive Development, 22, 258-270. http://dx.doi.org/10.1016/j.cogdev.2006.10.009

Meins, E., Fernyhough, C., Johnson, F., \& Lidstone, J. (2006). Mind-mindedness in children: Individual differences in internal-state talk in middle childhood. British Journal of Developmental Psychology, 24, 181-196. http://dx.doi.org/10.1348/026151005X80174

Miller, S. (2009). Children's understanding of second-order mental states. Psychological Bulletin, 135, 749-773.

Nucci, L. (2009). Nice is not enough: Facilitating moral development. Upper Saddle River, NJ: Pearson.

Oberle, E., Schonert-Reichl, K., Stewart Lawlor, M., \& Thomson, K. (2011). Mindfulness and inhibitory control in early adolescence. The Journal of Early Adolescence, 30, 125-136. http://dx.doi.org/10.1177/0272431611403741

Pasterski, V., Golombok, S., \& Hines, M. (2011). Sex differences in social behavior. In P. Smith \& C. Hart (Eds.), Blackwell Handbook of Childhood Social Development. ( $2^{\text {nd }}$ ed.). Oxford: Blackwell.

Pons, F., Harris, P. L., \& de Rosnay, M. (2004). Emotion comprehension between 3 and 11years: Developmental periods and hierarchical organization. European Journal of Developmental Psychology, 2(1), 127-152. 
Pons, F., Lawson, J., Harris, Pl., \& de Rosnay, M. (2003). Individual differences in children’s emotion understanding: Effects of age and language. Scandinavian Journal of Psychology, 44, 347-411.

Russell,T., Tchanturia, K., Rahman, Q., \& Schmidt, U. (2007). Sex differences in theory of mind: A male advantage on Happe’s “cartoon” task. Cognition and Emotion, 21, 1544-1564.

Salovey, P., \& Sluyter, D. (1997). Emotional development and emotional intelligence: Educational implications. New York: Basic Books.

Sutton, J., Smith, P., \& Swettenham, J. (1999). Bullying and 'theory of mind'; a critique of the 'social skills deficit' view of anti-social behaviour. Social Development, 8, 117-127.

Tannen, D. (1994). Gender and discourse. New York: Oxford University Press.

Walker, S. (2005). Gender differences in the relationship between young children's peer-related social competence and individual differences in theory of mind. Journal of Genetic Psychology, 166, 297-312.

Watson, A., Nixon, C., Wilson, A., \& Capage, L. (1999). Social interaction skills and theory of mind in young children. Developmental Psychology, 35, 386-391.

Willats, J. (2005). Making sense of children's drawings. Mahwah, New Jersey: Lawrence Erlbaum Associates.

Yuill, N., \& Coultas, J. (2007, June). The relation between emotion recognition and social experience in early adolescence. Poster presented at the annual meeting of the Jean Piaget Society, Amsterdam, ND.

Zambo, D., \& Brem, S. (2004). Emotion and cognition in students who struggle to read: New insights and ideas. Reading Psychology, 25, 189-200. 